\title{
Self-Monitoring of Reinforced Concrete Beam Bending with Carbon Nanofiber Polyurethane Composite
}

\author{
Nan Yang (iD) and Xiaolei Yang (iD ${ }^{2}$ \\ ${ }^{1}$ School of Architecture and Civil Engineering, Qiqihar University, No. 42, Wenhua Street, Qiqihar 161006, China \\ ${ }^{2}$ Department of Preventive Medicine, School of Public Health, Qiqihar Medical University, Qiqihar, 161006, China \\ Correspondence should be addressed to Xiaolei Yang; amy.1985@163.com
}

Received 29 September 2021; Revised 7 December 2021; Accepted 10 January 2022; Published 22 January 2022

Academic Editor: Chao Wu

Copyright (C) 2022 Nan Yang and Xiaolei Yang. This is an open access article distributed under the Creative Commons Attribution License, which permits unrestricted use, distribution, and reproduction in any medium, provided the original work is properly cited.

\begin{abstract}
To examine the intelligent sensing properties of polyurethane cement mixed with carbon nanofiber and used as beam reinforcement material, 7 reinforced concrete T-beams were made and reinforced with carbon nanofiber polyurethane cement material (CPUC). Four-point bending tests were conducted. Reinforcing concrete beams with CPUC material might increase the yield load and ultimate load of beams significantly. The overall stiffness of the reinforced beam was enhanced. CPUC played a significant inhibitory role in the formation and development of beam cracks. A sudden change in the rate of CPUC resistance can be used to monitor the yield of a steel bar, and then, a safety warning for the components can be launched. By establishing a model of the relationship between the resistance change rate and the external load, the bearing capacity of the beam is evaluated in real time, and the dual effects of reinforcement and health monitoring of the beam are realized simultaneously.
\end{abstract}

\section{Introduction}

Polyurethane matrix (polyurethane matrix, PUM) composite reinforcement material is a new reinforcement material that was developed in recent years; it is a type of highstrength reinforcement material made of polyurethane matrix, which is used as cementitious material by adding appropriate amounts of ultrafine aggregate (such as cement, silica fume) into the matrix.

PUM is used by pouring approximately $25 \mathrm{~mm}$ thick PUM material on the sides of concrete beams or columns for reinforcement. The essence of the reinforcement method is between the external reinforcement method and the increasing section method, but the area of increased section is small and has little influence on the structure's appearance or bridge clearance, and it has a good reinforcement effect (see Figure 1). Compared with the traditional reinforcement methods for beams and columns, PUM material has the advantages of making a strong bond with concrete and having good fluidity, environmental friendliness, light weight, high toughness, and easy construction. It has been gradually applied to reinforcement and reconstruction projects of concrete bridges and piers [1-4].

However, PUM material is limited only to actively increasing the strength and stiffness of the bridge and pier columns and does not have an intelligent effect after reinforcement. Therefore, it is difficult to make timely and quantitative evaluations of the condition of the columns during their service period, which increases the cost of monitoring and testing after the reinforcement of the bridge.

As people prioritize structural safety and comfort, intelligent materials have attracted increasing attention in the field of civil engineering, and the detection and monitoring of structural health and safety have become an important part of civil engineering, specifically, disaster prevention and mitigation [5-8].

Ordinary PUM reinforcement materials do not possess conductive properties. By adding appropriate amounts of special conductive fillers (such as carbon nanofiber), it is possible to make conductive polyurethane-based composites. The addition of conductive filler can not only improve the mechanical properties, toughness, ductility, crack 


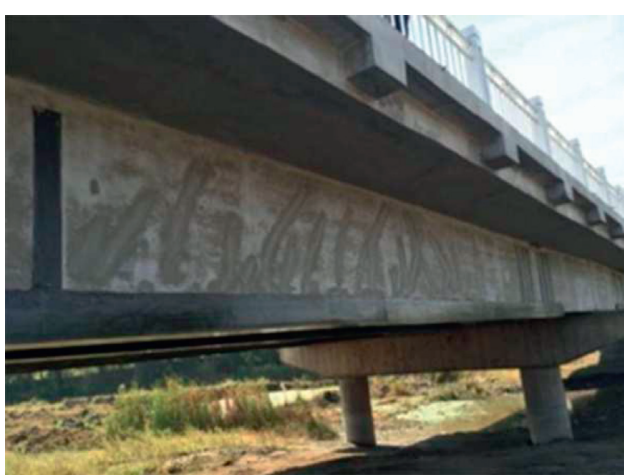

(a)

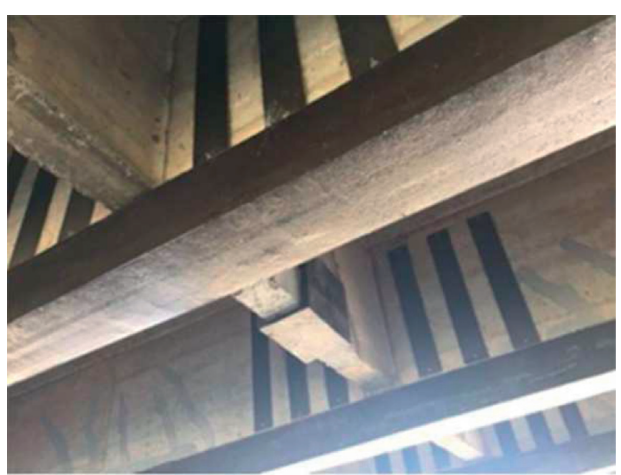

(b)

Figure 1: Case of solid bridge reinforcement. (a) Overall effect. (b) Beam bottom reinforcement.

resistance, and durability of the PUM but also significantly reduce its resistivity. Under the action of an external force, the elastic modulus is small, which not only forms the first line of defense against an external load but also realizes the self-inductance of the stress and strain of the reinforced structure by monitoring the resistivity change of the CPUC material, and the development process of the CPUC internal damage can be characterized. This approach can prevent the potential brittle failure of a structure and meet the needs of structural safety self-detection. Through its superb bondability with concrete, the functions of self-awareness, selfdiagnosis, and self-monitoring of steel bars and concrete cracks in reinforced beams can be established by using physical, geometric, and mechanical relationships, such as the flat section assumption and the elastic modulus. CPUC material can be used not only as a load-bearing reinforcement material but also as a functional material for diagnosing and detecting the status of the reinforced components, giving it the dual effect of both reinforcement and monitoring.

Thus, CPUC can not only prolong the service life of a bridge and enhance the seismic resistance of the structure but also monitor the development of and changes in the damage of the key components of the bridge in real time. It will save a large amount of manpower, materials, and financial resources and enhance the safety and reliability of the bridge.

For the monitoring of concrete beams, most scholars have used the method of embedding piezoelectric sensors or adding conductive fillers into the concrete matrix. Under the action of an external load, changes in the resistivity of the sensors or matrix occur and are used to monitor parameters such as the strain and cracks in the beams [9-13]. However, there are few reports on the health monitoring of the beam body after in vitro reinforcement.

Di et al. [14] have reported experimental research on concrete beams embedded with prestretch $\mathrm{Ni}$-Ti shape memory alloy (SMA) wires during the martensite phase at room temperature. The relationship between the resistance change rate of the SMA and the crack width of the concrete beam was tested, and self-repair of the crack was realized while the SMA was excited, while the influence of different prestretching and clamping was accounted for in the experiment. The result indicated that the resistance change rate of the SMA was sensitive to the changes in the crack width, and the recovery property of the phase variation could realize the ability for crack self-repairing. The sensitive property of the resistance change rate and the recovery property could be used for concrete beam monitoring and self-repairing temporarily. Divsholi et al. [15] conducted an experiment on four real size concrete frame structures with different details, subjected to gradually increased loads. A number of piezoelectric ceramic lead zirconate-titanate (PZT) sensors were bonded to the frame structure to acquire a PZT electromechanical (EM) admittance signature. The structural mechanical impedance (SMI) was extracted from the PZT EM admittance signature, and its sensitivity was compared with that of the EM admittance. The relationships between the damage index and the loading step and tip deflection of the concrete structure were obtained. Finally, the sensitivity of the PZT sensors in the detection of the critical loading level was discussed. The results showed that the PZT sensors were capable of monitoring the integrity and behavior of the real size concrete structures. One research study used intelligent aggregates as sensors to identify the structural damage mechanism of basalt fiber (BFRP) strengthened concrete beams. The test results showed that the cracking and failure position of the BFRP concrete beam can be located by the SA sensor, and the corresponding load can be identified according to the signal change. By obtaining the focusing signal amplitude of the whole region, the stiffness degradation and deflection change in the BFRP concrete beams could be effectively characterized [16]. Zhang and Lehua [17] explored the electromechanical effect of the bending process of a graphene or steel fiber concrete beam. These authors showed that the bending sensitivity of the beam is significantly improved by the addition of graphene, and the deflection change of the conductive beam could be monitored by using the resistance change rate of the conductive beam in the bending process.

In addition, Aggelis et al. [18] reported that the acoustic emission (AE) and digital image correlation (DIC) were applied during four-point bending tests of large beams to follow the damage accumulation. In this study, AE helped to determine the onset of a fracture as well as the different damage mechanisms through the registered shifts in the $\mathrm{AE}$ 
rate, the locations of active sources, and changes in the waveform parameters. Simultaneously, crucial information that concerns the moments of stress release of the patches due to debonding is supplied by DIC, which benchmarks the trends monitored by AE. Wiwattanachang [19] has demonstrated an application of the electrical imaging method to monitor the development of cracks in fiber concrete beams. This study showed that resistivity measurements on the concrete specimens were able to detect an increase of concrete resistivity with the curing time. To address the effect of beam size, new procedures to correct the resistivity measurements before inversion were proposed and successfully applied in this study. The results indicated that both the crack direction and depth could be accurately determined in the inverted resistivity sections.

In previous researches, polymer-based composites have been used only as a substrate for bonding fiber-reinforced materials or as embedded protective materials for wire ropes and reinforced mesh. Composite materials play a limited strength in the process of reinforcement force. Fibers often have a single effect of strengthening toughness and do not apply the conductive properties of certain fibers. Furthermore, there are few reporters that the damage of the structure is monitored by using the characteristics of resistance changes of fiber under external forces.

In this paper, we made seven pieces of reinforced concrete T-beams and strengthened six of them with PUC material, and we conducted the four-point bending test. The changes in the beam bearing capacity, ductility, and stiffness after reinforcement were discussed. At the same time, the resistance change rate of the CPUC strengthening material is used to predict the stress and strain state of the steel bar, evaluate the bearing capacity of the beams, and generate early safety warnings for members. Thus, the dual effects of reinforcement and beam health monitoring are realized.

\section{Materials and Methods}

\subsection{Materials}

\subsubsection{Cementitious Material (Two-Component} Polyurethane). The polymethylene isocyanate used in this paper was produced by the Wanhua Chemical Group (WANNATEPM-200). It is chemically active and can easily react with water to form insoluble urea compounds and release carbon dioxide. The main material composition is shown in Table 1, and the physical and chemical properties are shown in Table 2.

Polyester polyurethane can easily be made to hydrolyze, and alkaline cement hydrate is more likely to be destroyed; thus, polyether polyol was selected as the polyol compound in this study. Additionally, the PU synthesized by polyether has good resistance to hydrolysis and low temperature. Composite polyether, which is produced by Shandong Yisheng Polyurethane Co. Ltd., is mainly composed of polyether polyol, silicone oil, and the epoxy catalyst EZ01. The main material composition of the composite polyether is shown in Table 3, and the physical and chemical
TABLE 1: WANNATEPM-200 composition.

\begin{tabular}{lcc}
\hline Serial number & Name of substance & Mass percent \% \\
\hline 1 & $\begin{array}{c}\text { Isocyanate } \\
\text { Diphenylmethyl-4,4- } \\
\text { diisocyanate }\end{array}$ & $50 \%-70 \%$ \\
\hline
\end{tabular}

TABLE 2: WANNATE PM-200 physicochemical property.

\begin{tabular}{lcc}
\hline $\begin{array}{l}\text { Serial } \\
\text { number }\end{array}$ & Item & Index \\
\hline 1 & Surface & Brown liquid \\
2 & Viscosity $\left(25^{\circ} \mathrm{C}\right) / \mathrm{mPa} \cdot \mathrm{s}$ & $150-250$ \\
3 & Content of isocyanate root & $30.5-32.0$ \\
& $(-\mathrm{NCO}) / \%$ & $1.220-1.250$ \\
5 & Density $\left(25^{\circ} \mathrm{C}\right) /\left(\mathrm{g} / \mathrm{cm}^{3}\right)$ & $\leq 0.030$ \\
6 & Acidity $/ \%$ & $\leq 0.20$ \\
\hline
\end{tabular}

TABLE 3: Composition of combined polyether.

\begin{tabular}{lcc}
\hline Serial number & Name of substance & Mass percent $\%$ \\
\hline 1 & Polyether glycol & $90 \%-95 \%$ \\
2 & Silicone oil & $1 \%-3 \%$ \\
3 & EZ01 of epoxy catalysts & $1.5 \%-3 \%$ \\
\hline
\end{tabular}

properties are shown in Table 4. The water content of polyether polyol should be strictly controlled, and it is usually less than $0.05 \%$.

2.1.2. Filler Materials. The mass ratio of polyurethane to cement is $1: 0.7$, and $5 \%$ cement is replaced by silicon ash. The cement uses 42.5 ordinary Portland cement produced by the Harbin Yatai cement plant. The initial setting time is 185 minutes, and the final setting time is 265 minutes. The composition is shown in Table 5. Silica fume is provided by Xinlei Mineral Powder processing plant in Xingtang County, and its chemical composition is shown in Table 6. The specific surface area is $1.5 \times 104 \mathrm{~m}^{2} / \mathrm{kg}$, and the silicon content is more than $96 \%$. The cumulative pass rate of the cement and silica fume particles is shown in Table 7.

2.1.3. Conductive Packing. The conductive filler $\mathrm{CNF}$ is produced by Nanjing Xianfeng Nanomaterials Technology Co., Ltd., and the physical properties are shown in Table 8. It was mixed with a small amount of $3 \mathrm{~mm}$ short-cut carbon fibers produced by Dongli Company of Japan, the various physical properties of which are shown in Table 9. The polycement ratio is set at $1: 0.7,5 \%$ of the mass of the cement is replaced by silica fume, and the conductive filler is $1.5 \% \mathrm{CNF}$ $0.2 \% \mathrm{CF}$, which is the best matching ratio of CPUC.

\subsection{Methods}

2.2.1. Preparation Process. First, the CNF was oxidized by concentrated acid, and its surface was modified by ultrasonic dispersion and other techniques to improve its dispersion effect in polyurethane matrix. The preparation process is as follows. 
TABLe 4: Physicochemical properties of combined polyether.

\begin{tabular}{lcc}
\hline Serial number & Item & Index \\
\hline 1 & Surface & Colorless transparent liquid \\
2 & Viscosity $\left(25^{\circ} \mathrm{C}\right) / \mathrm{mPa} \cdot \mathrm{s}$ & $200-1500$ \\
3 & Hydroxyl value, $\mathrm{mg} \mathrm{KOH} / \mathrm{g}$ & $350 \pm 30$ \\
4 & Density $\left(25^{\circ} \mathrm{C}\right) /\left(\mathrm{g} / \mathrm{cm}^{3}\right)$ & $1.11 \pm 0.20$ \\
\hline
\end{tabular}

TABLE 5: Chemical composition of cement.

\begin{tabular}{lccccccccccc}
\hline Chemical composition & $\mathrm{CaO}$ & $\mathrm{SiO}_{2}$ & $\mathrm{Al}_{2} \mathrm{O}_{3}$ & $\mathrm{Fe}_{2} \mathrm{O}_{3}$ & $\mathrm{MgO}$ & $\mathrm{SO}_{3}$ & $\mathrm{Na}_{2} \mathrm{O}$ & $\mathrm{K}_{2} \mathrm{O}$ & $\mathrm{Cl}$ & $\mathrm{f}-\mathrm{CaO}$ & Loss on ignition \\
\hline Mass percent \% & 60.19 & 20.58 & 5.58 & 2.84 & 2.47 & 2.18 & 0.18 & 0.48 & 0.03 & 1.94 & 4.04 \\
\hline
\end{tabular}

TABle 6: Chemical composition of silica fume.

\begin{tabular}{lccccccc}
\hline Chemical composition & $\mathrm{SiO}_{2}$ & $\mathrm{Al}_{2} \mathrm{O}_{3}$ & $\mathrm{Fe}_{2} \mathrm{O}_{3}$ & $\mathrm{MgO}$ & $\mathrm{CaO}$ & $\mathrm{NaO}$ & $\mathrm{PH}$ average \\
\hline Mass percent \% & $85 \sim 96$ & 1.0 & 0.9 & 0.7 & 0.3 & 1.3 & Neutral \\
\hline
\end{tabular}

TABLE 7: Cumulative pass rate of fine aggregate particles.

\begin{tabular}{lcccccccc}
\hline Particle size $(\mu \mathrm{m})$ & 0.3 & 0.6 & 1 & 4 & 8 & 16 & 32 & 64 \\
\hline Cement & 0 & 0.37 & 2.97 & 16.35 & 27.34 & 47.55 & 75.36 & 95.32 \\
Silica fume & 35.2 & 60.2 & 89.6 & 100 & 100 & 100 & 100 & 100 \\
\hline
\end{tabular}

TABle 8: Physical parameters of carbon nanofibers.

\begin{tabular}{lcccccc}
\hline Purity & Diameter & Length & Draw ratio & Resistivity & Specific surface area & Stacking density \\
\hline $99.9 \%$ & $150-200 \mathrm{~nm}$ & $10-20 \mu \mathrm{m}$ & 70 & $6 \times 10^{-6} \Omega \cdot \mathrm{m}$ & $300 \mathrm{~m}^{2} / \mathrm{g}$ & $0.18 \mathrm{~g} / \mathrm{cm}^{3}$ \\
\hline
\end{tabular}

TABLE 9: Basic properties of PAN-based carbon fibers.

\begin{tabular}{lcccccc}
\hline Diameter & Tensile strength & Modulus of elasticity & Carbon content & Elongation & Density & Volume resistivity \\
\hline $7.0-10 \mu \mathrm{m}$ & $3.6-3.8 \mathrm{GPa}$ & $240-280 \mathrm{GPa}$ & $\geq 95 \%$ & $1.5 \%$ & $1.6-1.76 \mathrm{~g} / \mathrm{cm}^{3}$ & $1.5 \times 10^{-3} \Omega \cdot \mathrm{cm}^{2}$ \\
\hline
\end{tabular}

The CNF was dried to constant weight at $120^{\circ} \mathrm{C}$ to remove the moisture absorbed during storage, soaked in a mixture of concentrated sulfuric acid and concentrated nitric acid (volume ratio $1: 3$ ) for $2 \mathrm{~h}$, and then cut into $100-300 \mathrm{~nm}$ tubes. Subsequently, carboxylation was obtained by oxidation with concentrated sulfuric acid and 30\% hydrogen peroxide (1:4 volume ratio) CNFs, washing with clean water, and drying at $100^{\circ} \mathrm{C}[20,21]$. We baked the cement (in an environment with a relative humidity of less than $20 \%$ ) at a high temperature $\left(500^{\circ} \mathrm{C}\right)$ for 1 hour to remove the free water, and then, we sealed and set it aside. The mixture of CNF and CF was added to the polyol and dispersed by an ultrasonic disperser at $60^{\circ} \mathrm{C}$ for $1 \mathrm{~h}$ [22]. The polyether mixed with CNF and $\mathrm{CF}$ was then removed at $120^{\circ} \mathrm{C}$ vacuum dehydration of $2 \mathrm{~h}$, and the vacuum degree was $0.1 \mathrm{MPa}$; then, the weighed cement and isocyanate were added quickly and stirred at a high speed for $120 \mathrm{~s}$. In the process of stirring, silica fume is slowly added, and a small amount of graphite is sprayed (for lubrication). Finally, the stirred CPUC is poured into the mold and smeared with a small amount of film remover, and bubbles gather and escape during the forming process. After 24 hours, the mold is removed and cured at room temperature for 3 days. The experimental temperature is $14-17^{\circ} \mathrm{C}$, and the relative humidity is $30 \%-50 \%$.
2.2.2. Design and Production of the Original Beam. We describe the design and manufacture of 7 concrete T-section beams. One of them is used as a contrast beam; six are strengthened beams, with a concrete strength design grade C40, a mix ratio the same as in Tables 4 and 5, a beam length of 3000 , a beam span of $2700 \mathrm{~mm}$, and a pure bend length of $900 \mathrm{~mm}$. In the longitudinal tensile steel bar 2C18, the average measured yield strength is $455 \mathrm{MPa}$, the average ultimate strength is $512 \mathrm{MPa}$, and the reinforcement ratio of the longitudinal steel bar is $0.95 \%$. To prevent shear failure due to insufficient shear strength, B8@150 mm stirrups are arranged along the beam length, and the bending-shear section is encrypted to $80 \mathrm{~mm}$. The specific parameters are shown in Figure 2.

2.2.3. Reinforcement Programs. In this experiment, the effects of different fiber lengths and types on the reinforcement effect of the beam bottom were investigated. At the same time, we studied the change rate of the CPUC resistance at the bottom of the strengthened beam and the change law of the steel bar strain and bearing capacity. To minimize the amount of CNF and not reduce the sensitivity of the CPUC resistivity measurement, the fiber types of the reinforced beams mixed with 


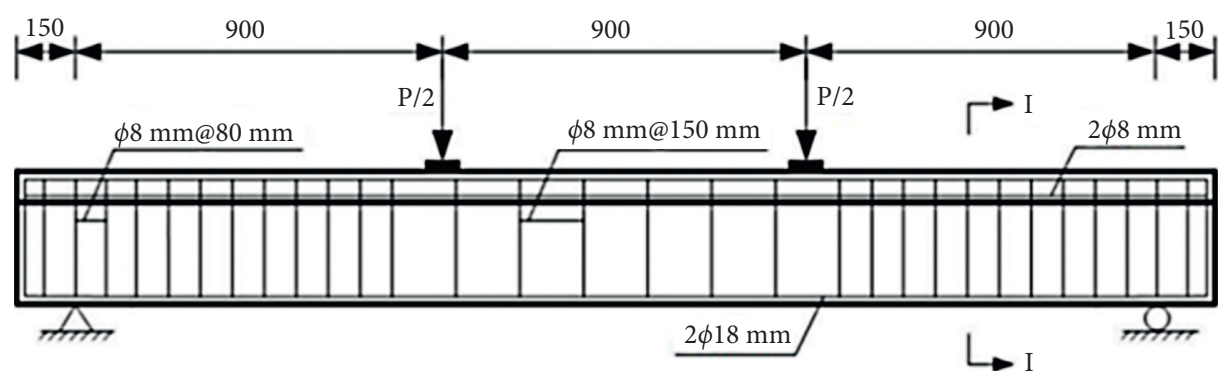

(a)

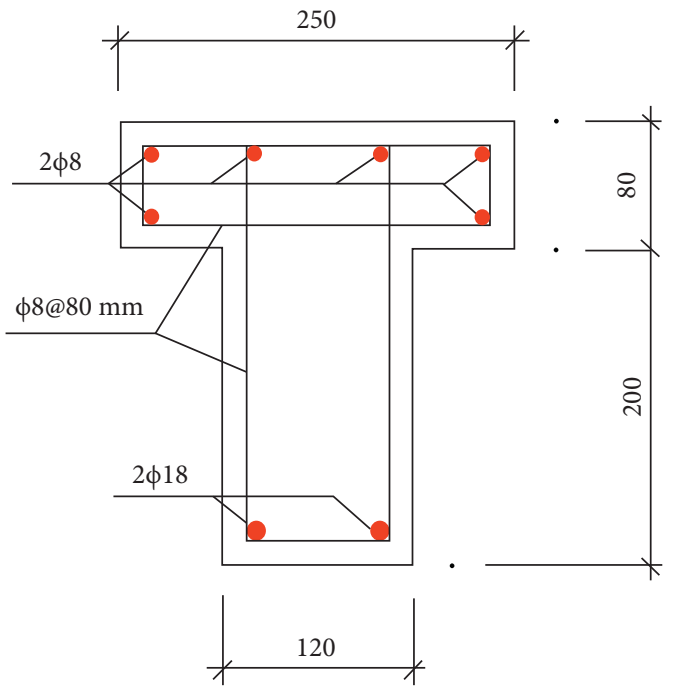

(b)

FIGURE 2: Section parameters of the beam to be reinforced. (a) Longitudinal section. (b) Section 1-1.

TABLE 10: Reinforcement of each beam.

\begin{tabular}{|c|c|c|c|}
\hline \multirow{2}{*}{ Beam no. } & \multirow{2}{*}{ Type of fiber } & \multicolumn{2}{|c|}{ Method of reinforcement } \\
\hline & & Length & Range \\
\hline $\mathrm{L}_{1}$ & - & $\mathrm{L}_{0}$ & \\
\hline $\mathrm{L}_{2}$ & $\mathrm{C}_{1}$ & $\mathrm{~L}_{0}$ & \\
\hline $\mathrm{L}_{3}$ & $\mathrm{C}_{2}$ & $\mathrm{~L}_{0}$ & \\
\hline $\mathrm{L}_{4}$ & $\mathrm{C}_{2}$ & $2 \mathrm{~L}_{0} / 3$ & Between the $\mathrm{L}_{0} / 6$ of the support \\
\hline $\mathrm{L}_{5}$ & $\mathrm{C}_{2}$ & $\mathrm{~L}_{0} / 2$ & Between the $\mathrm{L}_{0} / 4$ of the support \\
\hline $\mathrm{L}_{6}$ & $\mathrm{C}_{1}, \mathrm{C}_{2}$ & $\mathrm{~L}_{0}$ & Pure bend $C_{2}$; bending-shear section $C_{1}$ \\
\hline
\end{tabular}

fiber can be divided into $\mathrm{CNF}$ and $\mathrm{CF}$, in which single-doped $\mathrm{CF}$ is recorded as $\mathrm{C} 1$, mixed $\mathrm{CNF}$ and $\mathrm{CF}$ are recorded as $\mathrm{C} 2$, and an unstrengthened control beam is recorded as L0. The strengthened beam is shown in Table 10, and the cross section of the strengthened beam is shown in Figure 3.

We fully account for the excellent conductivity of the CNF and the "positive mixing effect" of the CF. To minimize the cost of the CNF, we use the method of piecewise simultaneous pouring, which involves bending and shearing at both ends of the PUC material while pouring the test beam. Meanwhile, the pure bending section is poured CPUC, and we apply a release agent interval between the pure bending section and bendingshear section with plastic baffle; next, the intermediate baffle can be removed after the initial setting time is reached (approximately $1.5 \mathrm{~h}$ depending on the temperature).

The concrete reinforcement process is as follows: First, the concrete beam bottom is completed by curing and is treated with chipping, as shown in Figure 4(a). The procedure is as follows: (1) Chisel hammer to coarse aggregate; (2) high pressure air pump to remove surface floating slurry and other debris; (3) repeated wipe with alcohol; (4) full dryness $24 \mathrm{~h}$ in a low humidity environment. Secondly, the wood form is assembled with an air nail gun. When the initial setting time is reached, 10 mesh copper mesh electrodes (size $60 \mathrm{~mm} \times 15 \mathrm{~mm}$ ) are buried at the designated position in the middle section of the span. The mold is removed after 24 hours and maintained for $3 \mathrm{~d}$ in a dry environment. 

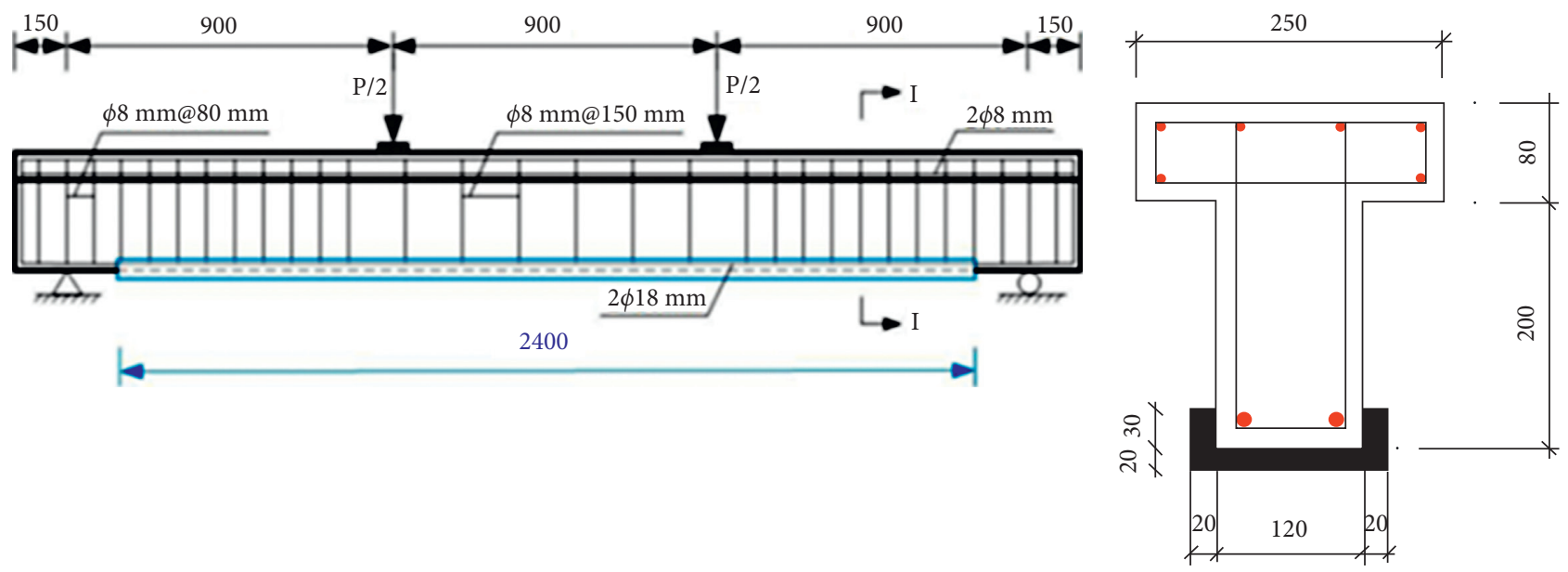

(a)

(b)

Figure 3: Section parameters of reinforced beam. (a) Longitudinal section of reinforced beam. (b) Section 1-1.

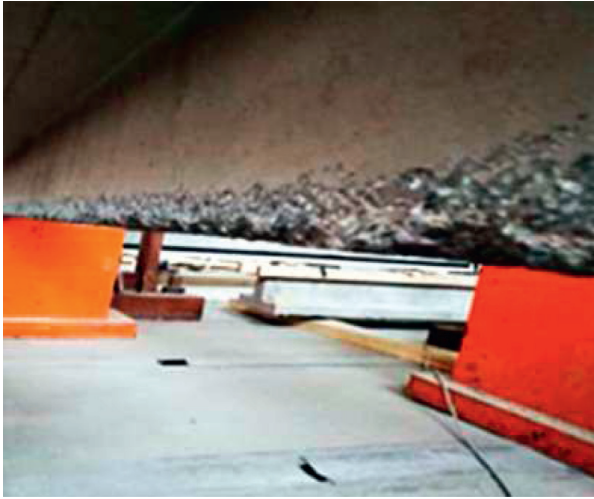

(a)

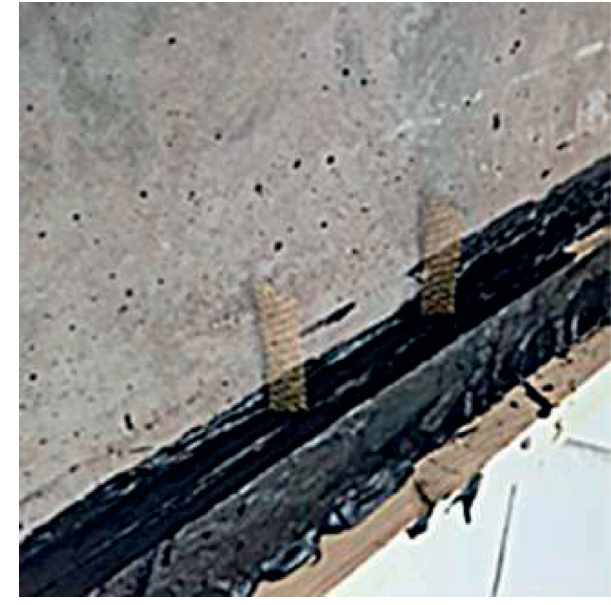

(b)

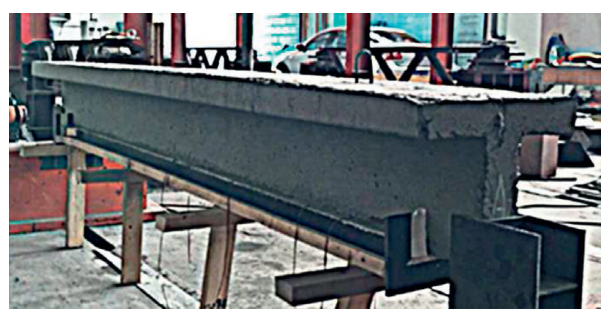

(c)

FIGURE 4: CPUC reinforcement process. (a) Chiseled treated beam bottom. (b) Imbedded electrode. (c) Support mold pouring.

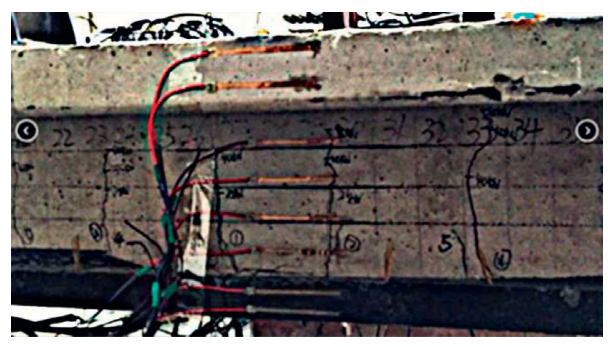

FIGURE 5: Distribution of strain gauge along beam height. 


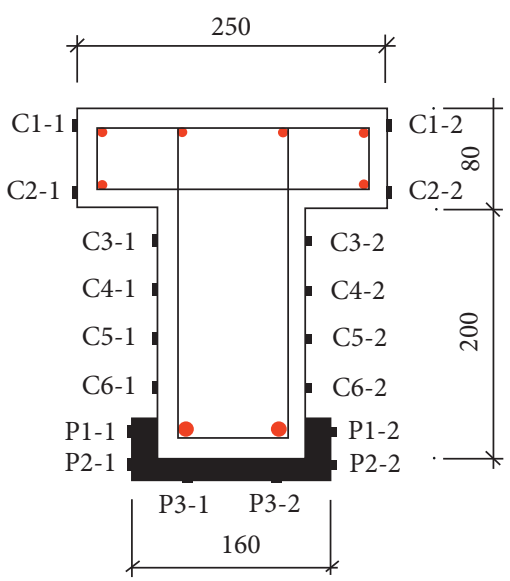

FIgURE 6: Test point layout schematic.

2.2.4. Site Layout and Data Acquisition. Eight strain gauges are arranged on each side of the pure bending section along the high spacing of the beam, as shown in Figure 5. The cross middle CPUC bottom face has a symmetrical arrangement of 2 strain gauges (specification: $56.1 \mathrm{~mm} \times 5.2 \mathrm{~mm}$ ), and the specific strain gauge arrangement is shown in Figure 6. The Dynamic and Static Data Acquisition System DH3817 produced by Jiangsu Donghua Testing Technology Co., Ltd., was used for the strain collection.

The CPUC resistance test in the middle of the pure bending section of the reinforced beam span adopts the fourelectrode method, in which the voltage pole spacing is $100 \mathrm{~mm}$, the current pole spacing is $250 \mathrm{~mm}$, and the current is supplied by a straightening current steady-voltage power supply of 0-60 V5A. The voltage change during loading is monitored in real time by a UT61 E digital multimeter, as shown in Figures 7 and 8, and the standard distance resistivity is calculated by the formula $\rho=\mathrm{RS} / \mathrm{L}$.

2.2.5. Loading Scheme and Measurement Content. All of the test beam support forms are simple, adopting a manual Jack $(1000 \mathrm{kN})$, using the distribution beam for four-point bending loading, with the load value of the Jack recorded by the load sensor. Before the formal start of the test, we preload $5 \mathrm{kN}$ and observe whether the strain gauge and meter reading is normal; troubleshooting is performed in a timely manner, and the same position measurement point strain error should be controlled within $10 \%$. The hierarchical monotone loading system is used in the test: every $5 \mathrm{kN}$ is the first-class load, and the current is kept constant during the loading process until the member reaches the limit bearing state. The loading process is shown in Figure 9.

At each stage of the load, the following are recorded: the strain values of the concrete and CPUC at each measuring point, the strain values of the longitudinal tensile steel bar, the displacement of the end support seat, and the mid-span deflection and the voltage values in the range of the standard distance. The average value of the strain reading of the two symmetry planes is taken as the final strain result.

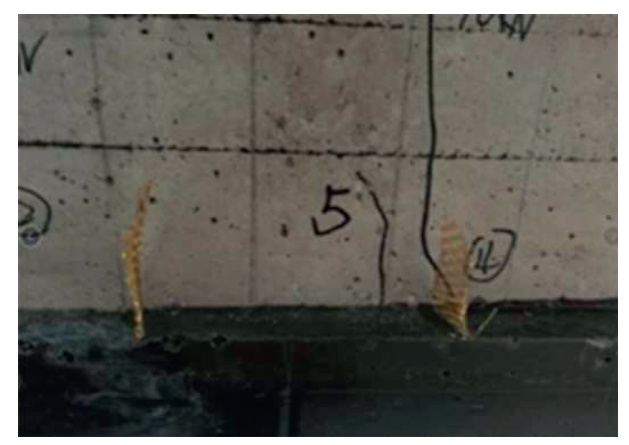

FIgURE 7: Voltage pole spacing.

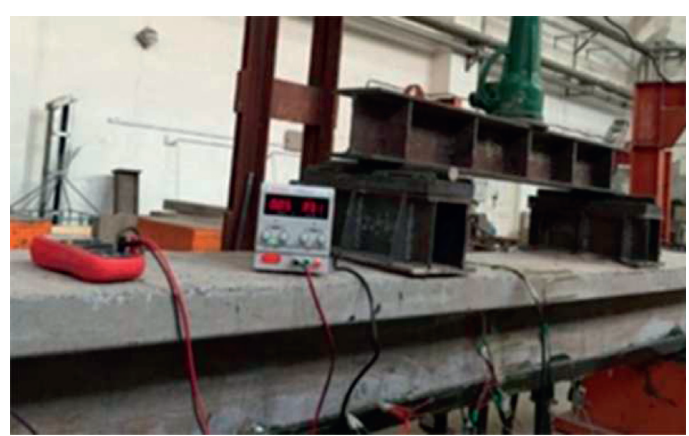

FIgURE 8: Resistance test diagram.

\section{Results and Discussion}

3.1. Bearing Capacity and Ductility Analysis. The test measured beam $\mathrm{L}_{0} \sim \mathrm{L}_{6}$ load-deflection curve is shown in Figure 10.

As shown in Figure 10, the experimental results indicated that the mid-span deflection of the reinforced beam is smaller than that of the unreinforced beam. The difference between the two increases with the increase in the load, and both the buckling load and the ultimate load of the reinforced beam can be increased. In addition, the ultimate load is higher than the yield load. The load-deflection curve can be divided into four stages.

3.1.1. Stage 1: Prior to Concrete Section Cracking. In this stage, the reinforced beam is similar to the homogeneous elastomer beam, and the deflection shows an obvious linear variation with increased load. Under the same load, the deflection of each beam is basically the same, and it can be found by the slope that the reinforced beam has a greater initial stiffness than the contrast beam.

3.1.2. Stage 2: Section Cracking-Yield of Longitudinal Bars. The stress on the concrete section was redistributed after cracking. The tensile force released by the concrete is shared by the steel bar and the CPUC, and the curve appears at the first inflection point, but it is not obvious, and the load continues to increase until the longitudinal reinforcement in the tensile zone begins to yield. At this time, because the elastic modulus of the CPUC bending is small, it is still in the elastic working stage. 


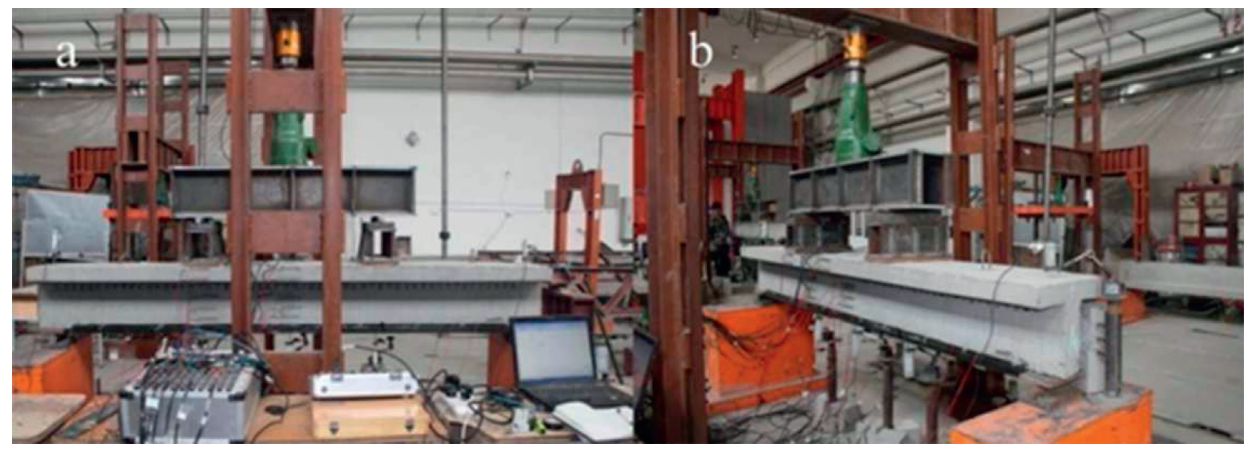

FIGURE 9: Loading process.

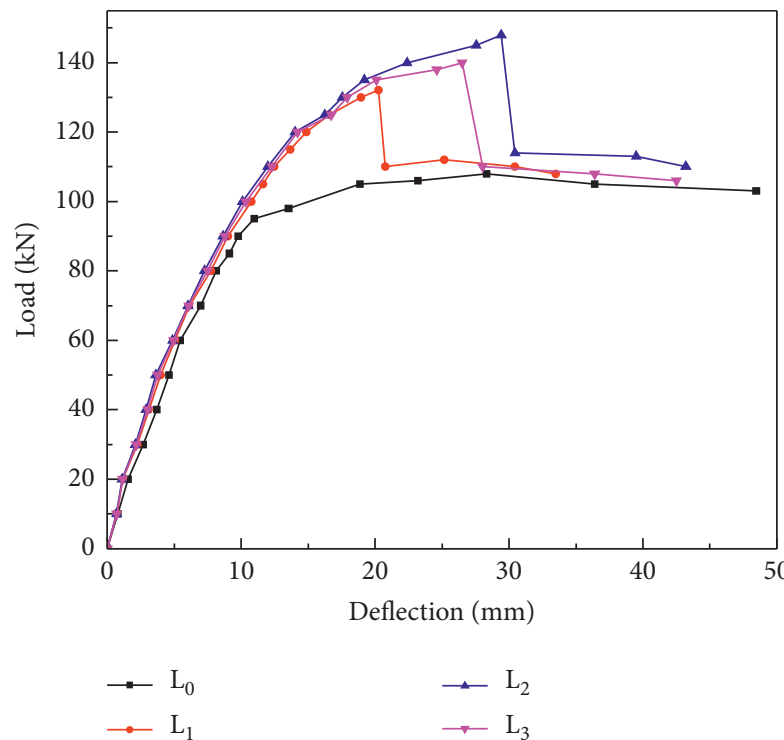

(a)

Figure 10: Load-deflection curve.

3.1.3. Stage 3: From the Longitudinal Bars' Yielding to the CPUC Yielding. After the longitudinal tensile bars yield, the deflection of the contrast beam increases sharply, while the deformation of the CPUC reinforced beams increases slowly. Since the nominal yield strain of the CPUC is 2.5 times higher than that of the steel bar, the CPUC strain increases steeply due to the transfer of the increased load to the CPUC in a short time. A larger pull force is produced to balance the increased external load, the deflection increases more rapidly, and the second inflection point appears to be more obvious in the curve. The reinforcement of the CPUC delays the rise of the neutralization axis to some extent, which raises the peak load, but the elastic modulus of bending by the CPUC is small, and its load is limited until the CPUC begins to yield.

3.1.4. Stage 4: Destruction Phase. After the CPUC begins to yield, fracture occurs when the load is further increased to its ultimate strain due to its short yield strengthening platform. At this time, the sudden drop section of the load in the curve is the reinforcement CPUC that can bear the load.

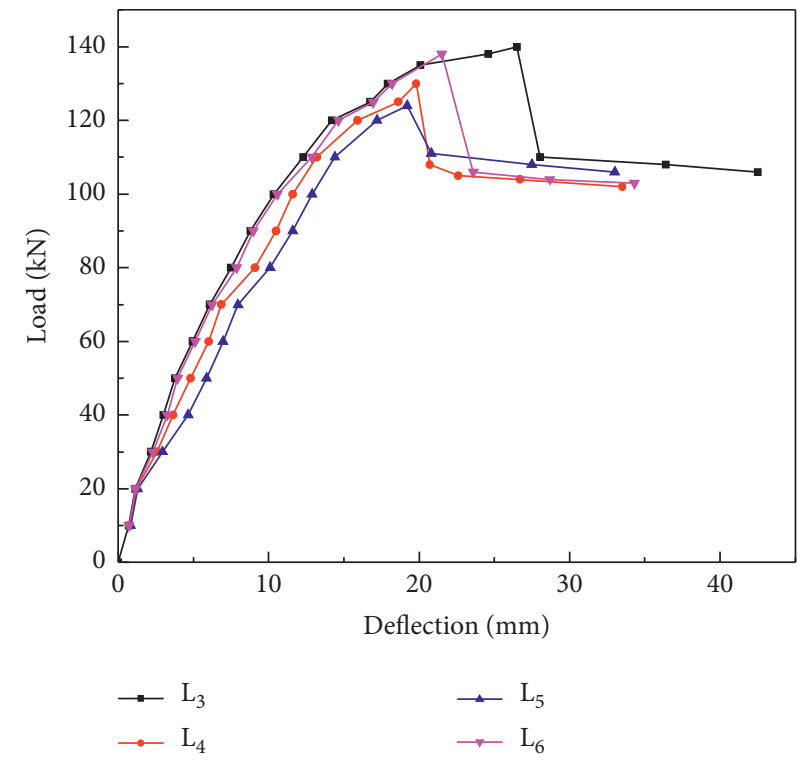

(b)

Subsequently, the deflection increases rapidly, the neutralization axis moves up quickly, and the height of the compression zone decreases further until it is destroyed.

A PUC-reinforced concrete beam has good functioning in terms of limiting crack formation and development, and the effect is more obvious after adding fiber. On the one hand, CPUC increases the cross section area of the concrete beams and then improves the bending moment of the inertia of the beam section. On the other hand, CPUC has a certain tensile capacity when limiting the formation of cracks, and it can bear part of the load after the yield of the steel bar. At the same time, the yield load and ultimate load of the beam are significantly enhanced.

The bearing capacity of $\mathrm{L}_{0} \sim \mathrm{L}_{6}$ measured by the test is shown in Table 11. During loading, no shear failure occurs in each beam, and the failure forms are all typical suitable reinforcement beam failures. Compared with the contrast beam $\mathrm{L}_{0}$, the cracking load, yield load, and ultimate load of each reinforced beam are increased by $26 \% \sim 74 \%, 13 \%$ $44 \%$, and $11 \% \sim 37 \%$, respectively. The crack load lifting amplitude is the largest, especially the $\mathrm{L}_{2}, \mathrm{~L}_{3}$, and $\mathrm{L}_{6}$, which indicates that the PUC after adding fiber has a strong 
TABLE 11: Test value of the bearing capacity for each stage of beam $\mathrm{L}_{0} \sim \mathrm{L}_{6}$.

\begin{tabular}{lccc}
\hline Beam number & Cracking load/kN & Yield load/kN & Extreme load/kN \\
\hline $\mathrm{L}_{0}$ & 42 & 78 & 108 \\
$\mathrm{~L}_{1}$ & 61 & 97 & 132 \\
$\mathrm{~L}_{2}$ & 73 & 112 & 148 \\
$\mathrm{~L}_{3}$ & 70 & 106 & 140 \\
$\mathrm{~L}_{4}$ & 58 & 95 & 130 \\
$\mathrm{~L}_{5}$ & 53 & 88 & 121 \\
$\mathrm{~L}_{6}$ & 67 & 104 & 137 \\
\hline
\end{tabular}

TABLE 12: Beam $\mathrm{L}_{0} \sim \mathrm{L}_{6}$ ductility index.

\begin{tabular}{lccc}
\hline Beam number & Yield deflection $\Delta \mathrm{y} / \mathrm{mm}$ & Limit deflection $\Delta \mathrm{u} / \mathrm{mm}$ & Ductility index $\Delta \mathrm{u} / \Delta \mathrm{y}$ \\
\hline $\mathrm{L}_{0}$ & 8.13 & 28.32 & 3.48 \\
$\mathrm{~L}_{1}$ & 11.63 & 20.25 & 1.74 \\
$\mathrm{~L}_{2}$ & 11.98 & 29.42 & 2.46 \\
$\mathrm{~L}_{3}$ & 12.3 & 26.5 & 2.15 \\
$\mathrm{~L}_{4}$ & 11.6 & 19.8 & 1.71 \\
$\mathrm{~L}_{5}$ & 12.9 & 19.2 & 1.49 \\
$\mathrm{~L}_{6}$ & 10.58 & 21.5 & 2.03 \\
\hline
\end{tabular}

inhibitory effect on the crack development. With the successive shortening of the $\mathrm{L}_{3}, \mathrm{~L}_{4}, \mathrm{~L}_{5}$ reinforcement range (full length, $21_{0} / 3,1_{0} / 2$ ), the corresponding cracking load, yield load, and ultimate load are gradually reduced. The reason is that the extension reinforcement length outside the pure bending section is equivalent to the anchoring constraint on the reinforcement area of the pure bending section, and the anchoring constraint of the whole beam reinforcement is the strongest, while the effect of lifting the bearing capacity is obvious. With regard to $\mathrm{L}_{6}$ compared with $\mathrm{L}_{3}$, the amount of $\mathrm{CNF}$ is reduced by $2 / 3$, and the bearing capacity is reduced by only $4 \%$, which has a better economic effect.

As shown in Table 12, in the $\mathrm{L}_{0} \sim \mathrm{L}_{6}$ beam ductility index, it can be seen that the flexural stiffness increases, the ductility index decreases, and the ductility index increases greatly for the PUC reinforcement, which indicates that the addition of fiber increases the bearing capacity. At the same time, the ultimate deflection can be increased, and the contribution to the ductility index is greater. When the whole beam is strengthened, the ductility index increases significantly, and the ductility index decreases with the shortening of the reinforcement length at the bottom of the beam.

3.2. The Study on Self-Monitoring of the Bending of the CPUC Reinforced Beam. The mechanical properties and conductance sensitivity after CPUC reinforcement are considered synthetically. Taking the beam $\mathrm{L}_{6}$ as a typical example, the average strain distribution of each measuring point in the cross section of the middle pure bending section under different external loads is shown in Figure 11.

As shown in Figure 11, when the loading starts (approximately $20 \mathrm{kN}$ ), the concrete strain along the beam section height is very small due to the small bending moment, and it changes in a straight line with the increase in the load; then, the concrete at the junction of the tensile zone edge and the CPUC begins to crack (approximately $70 \mathrm{kN}$ ). With the occurrence and development of the cracks, the strain gauge in the tensile

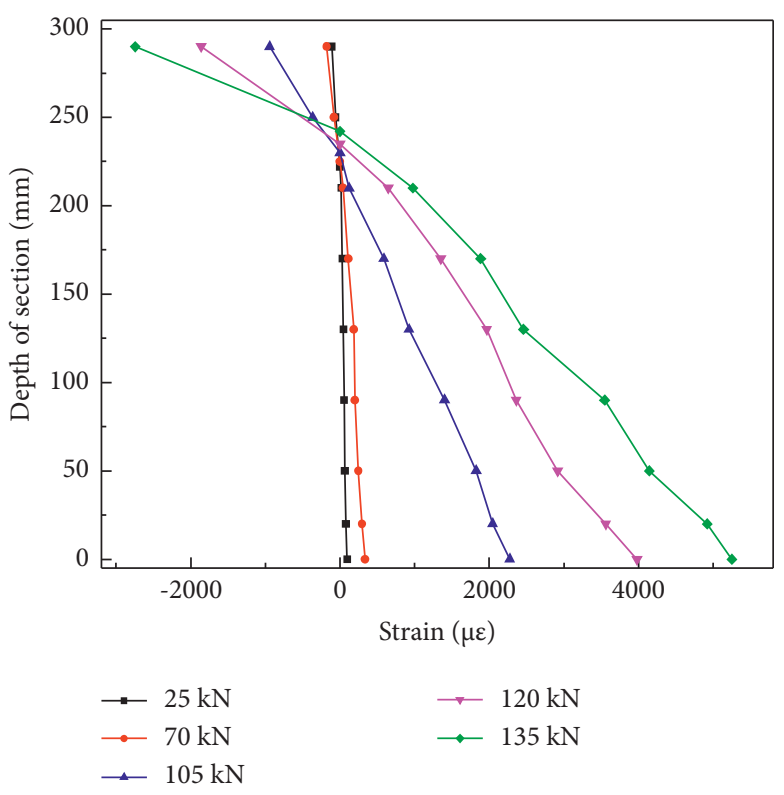

FIGURE 11: Average strain distribution across the medium section.

zone of the concrete gradually exits from the work, and the position of the neutral axis gradually moves up. When the load increases to $105 \mathrm{kN}$, the longitudinal tensile steel bar begins to yield, and the increased bending moment is almost entirely borne by the CPUC. As the CPUC strain reaches the limit, the strain is broken, and the strain increases rapidly; the neutral axis moves up rapidly until the concrete at the edge of the compression zone is completely crushed, which leads to damage of the beam. The whole process from the beginning of the loading to the failure satisfies the strain coordination relationship of the material. Under the action of all levels of load, the middle section of the pure bending section is basically in accordance with the assumptions for the flat section (as with other reinforced beams). The beam $\mathrm{L}_{6}$ load-reinforcement strain curve is shown in Figure 12. 


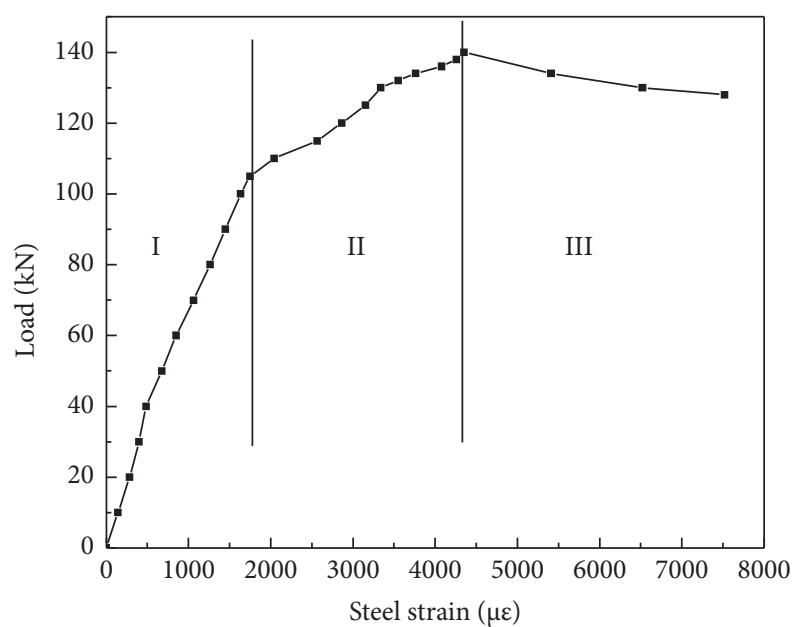

Figure 12: Load-steel bar strain curve.

The strain of the tensile steel bar increases linearly with the load at the beginning of the loading, as shown in Figure 12 . When the load of the $\mathrm{L}_{6}$ reinforced beam reaches $105 \mathrm{kN}$, a more obvious inflection point appears. Combined with the strain value of the steel bar, it shows that the tensile steel bar begins to yield (stage I) at this inflection point, and the load transfer continues to increase by the CPUC. Because of the lower flexural modulus of elasticity, the curve increase obviously slows down (stage II). When the load increases to the CPUC tensile limit, the CPUC rapidly enters the flow amplitude stage and then breaks, and the strain of the steel bar increases rapidly, and it is declared to be a failure of the beam body (stage III).

To eliminate the effect of the initial resistivity, the resistance change rate is taken as the dependent variable, and the relationship between the resistance change rate and the CPUC strain on the bottom surface of the strengthened layer and the strain of the steel bar is shown in Figure 13.

As shown in Figure 13, according to the flat section assumption of the above deformation coordination, the CPUC strain is slightly larger than the longitudinal strain, and the trend becomes more and more significant with increased strain. At the same time, both strains restrict each other and further improve the deformation performance of the CPUC reinforced beam. The CPUC resistance change rate can be used to evaluate the strain state of the steel bar, and especially when the steel bar yields, the resistivity changes, which warns the members in advance.

At the beginning of the loading, when the strain of the longitudinal tensile steel bar is less than $2350 \mu \varepsilon$, the beam body is basically in the elastic working state, and the resistance change rate increases slightly with increased strain. Stage I in the figure is for the beam safety working stage. When the strain of the longitudinal reinforcement is greater than $2350 \mu \varepsilon$, the resistivity is abrupt, the longitudinal reinforcement yields, and the increased external load transfer is borne by the CPUC. On the one hand, the CPUC strain increases to produce a larger tensile force, and on the other hand, the neutralization axis is moved up to produce a larger internal force arm to balance the increased external load. The resistance change rate increases rapidly with the CPUC strain, which corresponds to stage II in

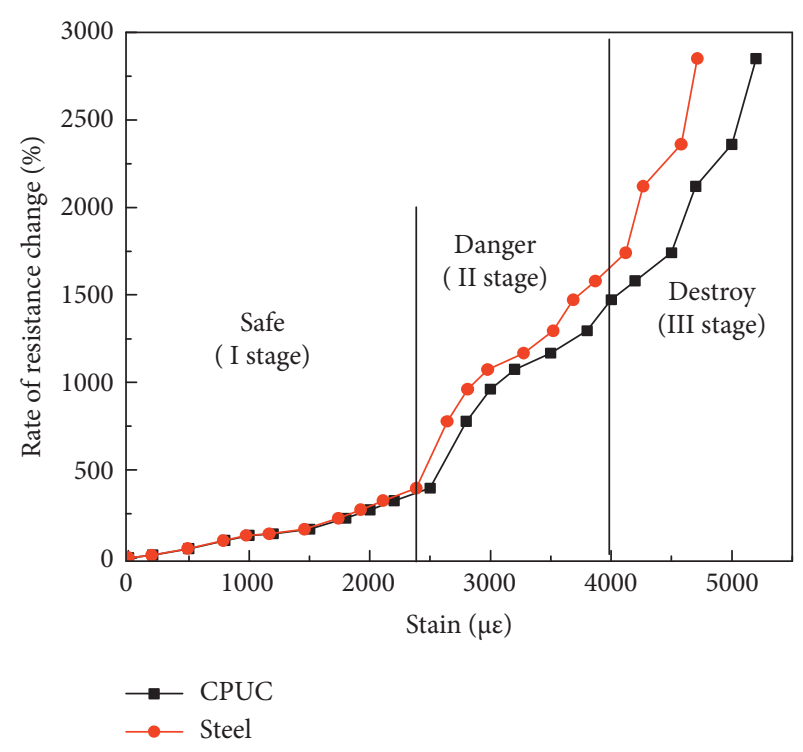

FIGURE 13: CPUC resistance change shown in the rate-strain relation curve.

the diagram, which serves as the beam warning stage. The CPUC yield occurs when the CPUC strain is greater than $4200 \mu \varepsilon$, the resistance change rate increases rapidly with the strain, and fracture occurs when its ultimate tensile strain is reached (approximately $5200 \mu \varepsilon$ ), which corresponds to stage III in the figure.

By further comparing the resistance change rate-load curve of Figure 14, it can be seen that when the resistance change rate is abrupt, it basically corresponds to the structural yield. This finding further verifies the feasibility of using the above CPUC resistivity change to monitor the yield of the steel bar, and it can also be evaluated according to the external load of the CPUC resistance change rate.

3.3. CPUC Resistance Change Rate Monitoring the Flexural Capacity. Based on the above test results, the following basic assumptions are used:

(1) The stress-strain relation of the concrete under compression is based on the relation suggested by Rusch, as follows:

$$
\sigma_{c}=\left\{\begin{array}{l}
f_{c}\left[2 \frac{\varepsilon_{c}}{\varepsilon_{0}}-\left(\frac{\varepsilon_{c}}{\varepsilon_{0}}\right)^{2}\right]\left(\varepsilon_{c} \leq \varepsilon_{0}\right), \\
f_{c}\left(\varepsilon_{0}<\varepsilon_{c} \leq \varepsilon_{c u}\right) .
\end{array}\right.
$$

Formula : $\varepsilon_{0}=0.002 ; \varepsilon_{c u}=0.0033$.

(2) The stress-strain curve of the steel bar is based on a double-line model, which is expressed as

$$
\sigma_{s}=\left\{\begin{array}{l}
E_{s} \varepsilon_{s}\left(\varepsilon_{s} \leq \varepsilon_{y}\right), \\
f_{y}\left(\varepsilon_{s}>\varepsilon_{y}\right) .
\end{array}\right.
$$




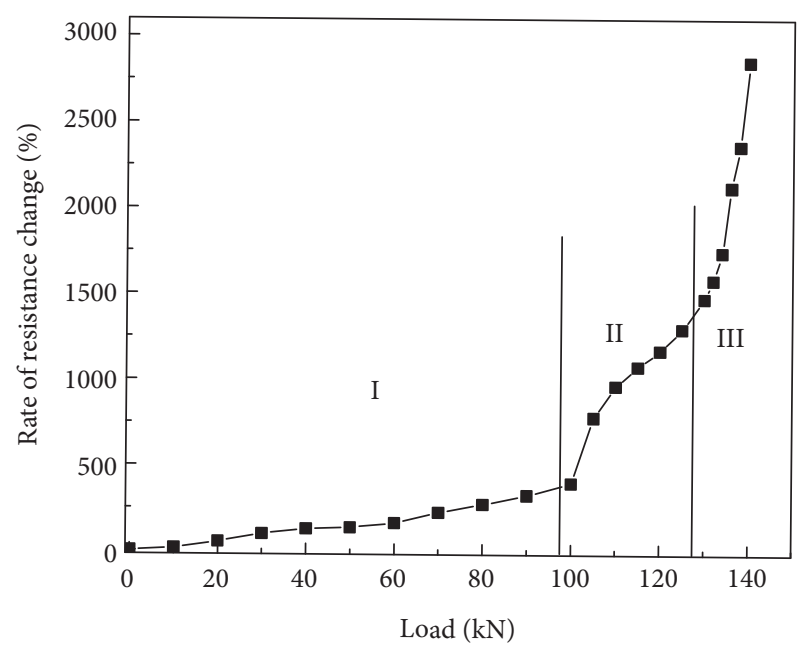

Figure 14: Resistance change rate-load curve.

Formula: When the calculated value is greater than 0.01 , it is taken as 0.01 .

(3) The CPUC is linear elastic material, and the tensile stress $\sigma_{p}$ is positive to the strain $\varepsilon_{p}$, which is expressed as $\sigma_{p}=E_{p} \varepsilon_{p} s$.

(4) Before the CPUC is broken, considering the deterioration of its bond with the concrete and the stripping failure due to the formation of mid-span cracks, $\sigma_{p}$, should be amended $[23,24]$. The relationship of $\varepsilon_{\mathrm{pb}}$ when CPUC is broken can be expressed as

$$
\varepsilon_{\mathrm{pb}}=\beta \sqrt{\frac{\sqrt{f_{\mathrm{pu}}}}{E_{p} t_{p}}} .
$$

Formula: $t_{p}$ is the CPUC calculation of the thickness; and $\beta$ is the width correction factor. If the CPUC is the same width as the beam, we take 0.707. Calculating $\varepsilon_{\mathrm{pb}}$ from formula (3) can also be satisfied for $\varepsilon_{\mathrm{pb}} \leq 0.9 \varepsilon_{\mathrm{pu}}$, where $\varepsilon_{\mathrm{pu}}$ is the CPUC ultimate tensile strain.

(5) The cross section deformation of the pure section in the middle span is in accordance with the assumption of the flat section, which can be obtained from the similar triangular relationship of the strain in Figure 15:

$$
\begin{aligned}
& \frac{\varepsilon_{s}}{\varepsilon_{p}}=\frac{h_{0}-x_{c}}{h_{0}-x_{c}+d}, \\
& \frac{\varepsilon_{c}}{\varepsilon_{p}}=\frac{x_{c}}{h_{0}-x_{c}+d} .
\end{aligned}
$$

Formula: The $d$ is the vertical distance between the joint force point of the tensile steel bar and the CPUC joint force point; $x_{c}$ is the height of the concrete compression zone; and $h_{0}$ is the vertical distance from the joint action point of the tensile steel bar to the edge of the concrete drawing area, $h_{0}=h-a_{s}$.

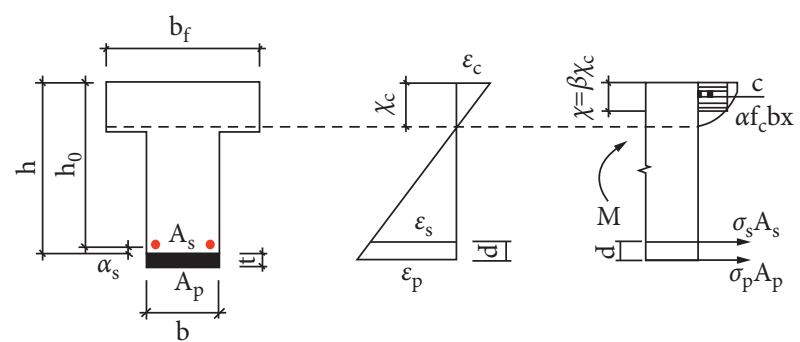

Figure 15: Bending calculation model.

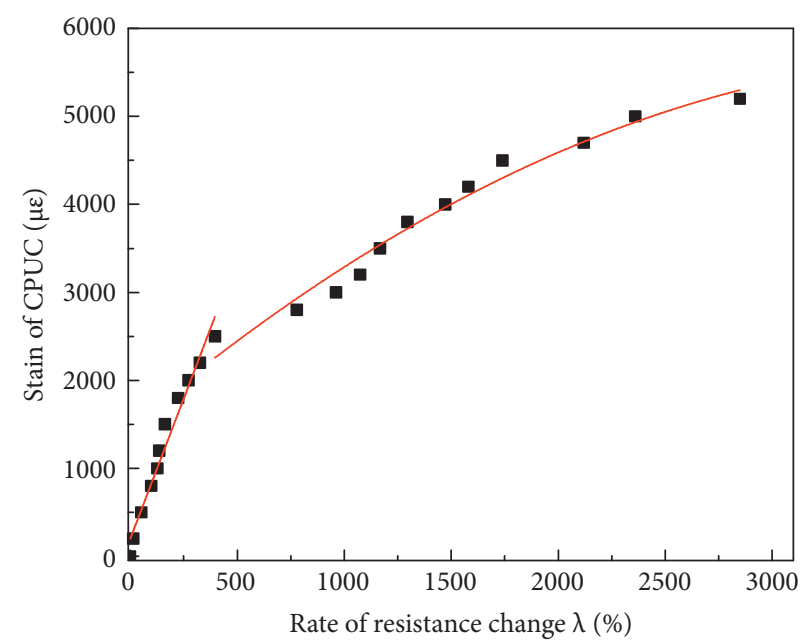

Figure 16: Diagram of fitting relationship between resistance change rate and strain.

Calculating from (5), after reinforcement, $x$ is less than or equal to $h_{f}$, which belongs to the first type of the T-section.

$$
\alpha f_{c} b_{f} h_{f}=f_{y} A_{s}+f_{\mathrm{pu}} A_{p} .
$$

From the balance of forces, we obtain

$$
\alpha \sigma_{c} b_{f} \beta x_{c}=\sigma_{S} A_{s}+\sigma_{p} A_{p} .
$$

If the concrete strength is less than or equal to C50, $\alpha=1.0, \beta=0.8 ; x_{c}$ is the depth of the compressive zone; $\sigma_{c}$ is the concrete compressive stress; $\sigma_{s}$ and $A_{s}$ are the tensile stress and area of the steel bar, respectively; $\sigma_{p}$ and $A_{p}$ are the tensile stresses and areas of the CPUC; and $\xi \leq \xi_{b}$. At the same time, it meets the minimum reinforcement ratio requirements. Additionally, $\sigma_{c}, \sigma_{s}, \sigma_{p}$ are based on the constitutive models (1) and (2), and we can obtain the equation of the $\varepsilon_{p}$ variable about $\varepsilon_{c}, \varepsilon_{s}$, and $x_{c}$.

$$
\begin{aligned}
M & =M \varepsilon_{p} \\
& =\sigma_{s} A_{s}\left(h_{0}-\frac{\beta x_{c}}{2}\right)+\sigma_{p} A_{p}\left(h_{0}+d-\frac{\beta x_{c}}{2}\right) .
\end{aligned}
$$

The CPUC resistance change rate $\lambda$ and its tensile strain relation can be fitted as shown in Figure 16, and the fitting formula is shown in (8). 
$\varepsilon_{p}=\varepsilon_{p}(\lambda)=\left\{\begin{array}{l}6.38 \lambda+198(0<\lambda \leq 400), \\ 2.53 \times 10^{-4} \lambda+2 \lambda+1480(400<\lambda \leq 3000) .\end{array}\right.$

Substituting formula (8) into formula (7) can obtain $M=M(\lambda)$, and from adjusting the value of the corresponding variable for the different failure modes, the moment value with the resistance change rate $\lambda$ as the independent variable can be obtained. After the CPUC reinforcement, the selfmonitoring function of the beam body can be realized by monitoring the changes in the resistance change rate.

\section{Conclusions}

In this study, the seven reinforced concrete T-beams were made out, and then six bottoms of them were reinforced by CPUC material. The four-point bending test was carried out to obtain the following conclusions:

(1) Reinforcing concrete beams with CPUC material could increase the yield load and ultimate load of beams significantly. The overall stiffness of the reinforced beam was enhanced. Compared with PUC reinforcement, CPUC has observably increased in beam limit load (up to $37 \%$ ). CPUC played a significant inhibitory role in the formation and development of beam cracks.

(2) The rate of change in resistivity of CPUC reflected the entire process of strain state during rebar force. The mutation of CPUC resistivity could be used to monitor rebar yield, and then the component could be safely warned.

(3) The relationship between resistivity change rate and external load $(M=M(\lambda))$ was established by the constitutive connection of original resistance change rate-tensile strain of CPUC material. This model could evaluate the bearing capacity of the beam body in real time and realized the dual effect of beam health monitoring at the same time.

\section{Data Availability}

All data, models, and code generated or used during the study appear in the submitted article.

\section{Conflicts of Interest}

The authors declare no conflicts of interest.

\section{Authors' Contributions}

X.Y. conceived the study; N.Y. performed the experiments, N.Y. performed formal analysis and wrote the main manuscript; and all authors approved the final manuscript.

\section{Acknowledgments}

This research was funded by Scientific Research Project of Qiqihar University (135509119) and University Nursing
Program for Young Scholars with Creative Talents in Heilongjiang Province (UNPYSCT-2018036).

\section{References}

[1] H. K. Hussain, G. W. Liu, and Y. W. Yong, "Experimental study to investigate mechanical properties of new material polyurethane-cement composite (PUC)," Construction and Building Materials, vol. 50, no. 2, pp. 200-208, 2014.

[2] H. K. Hussain, L. Z. Zhang, and G. W. Liu, "An experimental study on strengthening reinforced concrete T-beams using new material poly-urethane-cement (PUC)," Construction and Building Materials, vol. 40, no. 3, pp. 104-117, 2013.

[3] K. Zhang and Q. Sun, "Strengthening of a reinforced concrete bridge with polyurethane-cement composite (PUC)," The Open Civil Engineering Journal, vol. 10, no. 1, pp. 768-781, 2016.

[4] E. B. Jeon, S. Ahn, I. G. Lee, H. I. Koh, J. Park, and H. S. Kim, "Investigation of mechanical/dynamic properties of carbon fiber reinforced polymer concrete for low noise railway slab," Composite Structures, vol. 134, no. 5, pp. 27-35, 2015.

[5] H.-y. Chu and J.-k. Chen, "The experimental study on the correlation of resistivity and damage for conductive concrete," Cement and Concrete Composites, vol. 67, no. 9, pp. 12-19, 2016.

[6] D. D. L. Chung, "Carbon materials for structural self-sensing, electromagnetic shielding and thermal interfacing," Carbon, vol. 50, no. 9, pp. 3342-3353, 2012.

[7] N. Yang and Q. Sun, "Study on the self-monitoring of bending fatigue cumulative damage for carbon nanofiber polyurethane cement," Applied Sciences, vol. 9, no. 10, p. 2128, 2019.

[8] Y. Ding, Y. Huang, Y. Zhang, S. Jalali, and J. B. Aguiar, "Selfmonitoring of freeze-thaw damage using triphasic electric conductive concrete," Construction and Building Materials, vol. 101, no. 12, pp. 440-446, 2015.

[9] M. H. Sarwary, G. Yildinm, A. A. Dahawi et al., "Self-sensing of flexural damage in large-scale steel-reinforced mortar beams," ACI Materials Journal, vol. 116, no. 4, pp. 209-221, 2019.

[10] G. Yildirim, M. H. Sarwary, A. A. Dahawi, O. Ozturk, O. Anil, and M. Sahmaran, "Piezoresistive behavior of CF- and CNTbased reinforced concrete beams subjected to static flexural loading: shear failure investigation," Construction and Building Materials, vol. 168, no. 4, pp. 266-279, 2018.

[11] G. Yildirim, A. A. Dahawi, O. Ozturk, and M. Sahmaran, "Assessment of self-sensing capability of Engineered Cementitious Composites within the elastic and plastic ranges of cyclic flexural loading," Construction and Building Materials, vol. 145, no. 8, pp. 1-10, 2017.

[12] B. Han, Y. Wang, S. Ding et al., "Self-sensing cementitious composites incorporated with botryoid hybrid nano-carbon materials for smart infrastructures," Journal of Intelligent Material Systems and Structures, vol. 28, no. 6, pp. 699-727, 2017.

[13] Y. Ding, Z. Han, Y. Zhang, and J. B. Aguiar, "Concrete with triphasic conductive materials for self-monitoring of cracking development subjected to flexure," Composite Structures, vol. 138, no. 12, pp. 184-191, 2016.

[14] S. K. Di, H. Li, Y. F. Du, and S. Zou, "Self-monitoring and repairing based on crack of concrete beam embedded with SMA," Journal of Building Materials, vol. 12, no. 3, pp. 27-31, 2009.

[15] B. S. Divsholi, Y. W. Yang, and L. Bing, "Monitoring beamcolumn joint in concrete structures using piezo-impedance 
sensors," Advanced Materials Research, vol. 79-82, no. 6, pp. 59-62, 2009.

[16] L. Zhou, Y. Zheng, G. Song, D. Chen, and Y. Ye, "Identification of the structural damage mechanism of BFRP bars reinforced concrete beams using smart transducers based on time reversal method," Construction and Building Materials, vol. 220, no. 8, pp. 615-627, 2019.

[17] Y. Zhang and Y. U. Lehua, "Mechano-electric effect of steel fiber and graphene reinforced conductive concrete during flexural process," Concrete, vol. 335, no. 9, pp. 49-52, 2017.

[18] D. G. Aggelis, S. Verbruggen, E. Tsangouri, T. Tysmans, and D. Van Hemelrijck, "Monitoring the failure mechanisms of a reinforced concrete beam strengthened by textile reinforced cement using acoustic emission and digital image correlation," Smart Structures and Systems, vol. 17, no. 1, pp. 91-105, 2016.

[19] N. Wiwattanachang and P. H. Giao, "Monitoring crack development in fiber concrete beam by using electrical resistivity imaging," Journal of Applied Geophysics, vol. 75, no. 2, pp. 294-304, 2011.

[20] M. Szeląg, "Mechano-physical properties and microstructure of carbon nanotube reinforced cement paste after thermal load," Nanomaterials, vol. 7, no. 9, pp. 267-281, 2017.

[21] R. K. Abu Al-Rub, B. M. Tyson, A. Yazdanbakhsh, and Z. Grasley, "Mechanical properties of nanocomposite cement incorporating surface-treated and untreated carbon nanotubes and carbon nanofibers," Journal of Nanomechanics and Micromechanics, vol. 2, no. 1, pp. 1-6, 2012.

[22] N. Yang, K. Zhang, and Q. Sun, "Dispersion and pressure sensitivity of carbon nanofiber-reinforced polyurethane cement," Applied Sciences, vol. 8, no. 12, p. 2375, 2018.

[23] H. Akbarzadeh Bengar and A. A. Maghsoudi, "Experimental investigations and verification of debonding strain of RHSC continuous beams strengthened in flexure with externally bonded FRPs," Materials and Structures, vol. 43, no. 6, pp. 815-837, 2010.

[24] J. G. Teng, S. T. Smith, J. Yao, and J. F. Chen, "Intermediate crack-induced debonding in RC beams and slabs," Construction and Building Materials, vol. 17, no. 7, pp. 447-462, 2003. 